\title{
Catalytic Properties of Cu Complexes in Oxidative Carbonylation of Methanol
}

\author{
Xingxing $\mathrm{Hu}^{1, \mathrm{a}}$, Wuqiang Wen ${ }^{1, \mathrm{~b}}$, Hanmin $\mathrm{Lei}^{1, \mathrm{c}}$ and Zhiping $\mathrm{Du}^{1, \mathrm{~d}^{*}}$ \\ ${ }^{1}$ Key Laboratory for Green Chemical Process of Ministry of Education, Hubei Key Laboratory of \\ novel reactor \& green Chemical Technology, Wuhan Institute of Technology, Wuhan 430074, China \\ a1229365569@qq.com, bwenwuqiang@163.com, chanmlei@126.com, ddzpxyhry@163.com
}

Keywords: Dimethyl carbonate; $\mathrm{Cu}(\mathrm{II})-1,10-$ phenanthroline complex; Methanol; Oxidative Abstract. The thermostability of $\mathrm{Cu}(\mathrm{II})-1,10$-phenanthroline complexes was studied by the thermogravimetric analysis, and their catalytic properties were evaluated in oxidative carbonylation of methanol to dimethyl carbonate. It was found that the copper coordination environments and the thermostability of the complexes played important roles in their catalytic activities. $\mathrm{Cu}(1,10$-phenanthroline $) \mathrm{Cl}_{2}$ exhibited the highest activity due to the lowest steric hindrance, the highest coordination probability and the highest thermal stability. With the addition of $\mathrm{CuCl}$, the activity of $\mathrm{Cu}(1,10$-phenanthroline $) \mathrm{Cl}_{2}$ could be further improved and the turnover number of dimethyl carbonate increased from 39.0 to $46.9 \mathrm{~mol}_{\mathrm{DMC}} / \mathrm{mol}_{\mathrm{Cu}}$.

\section{Introduction}

Dimethyl carbonate (DMC) is a green chemical, and can be used as carbonylation reagent or methylation reagent to substitute for phosgene or dimethyl sulfate, respectively. Among several methods available for phosgene-free synthesis of DMC[1], the one-step oxidative carbonylation of methanol with $\mathrm{CO}$ and $\mathrm{O}_{2}$ is the most perspective route.

$\mathrm{CuCl}$ is known as a traditional catalyst in the oxidative carbonylation of methanol[2]. But this system has some disadvantages, such as the low solubility in methanol, high corrosiveness to metallic vessels due to the existence of $\mathrm{Cl}^{-}$, and so on.

The N-donor ligand is added to overcome these shortcomings. Xiong et al reported that the activity and the corrosiveness of $\mathrm{CuCl}$ could be improved effectively with the addition of $\mathrm{N}$-methyl imidazole (NMI)[3]. When N-butylpyridinium tetrafluoroborate was used as the reaction media, the solubility of $\mathrm{CuCl}$ in methanol was enhanced from 0.44 to $2.2 \mathrm{~g} / 100 \mathrm{~g}$, and the quantity of DMC was also raised from 2.3 to $4.6 \mathrm{~g} /\left(\mathrm{L}_{\text {cat }} \cdot \mathrm{h}\right)$ [4]. Considering that the solubility of $\mathrm{CuCl}$ in methanol is very low, $\mathrm{CuCl}_{2}$ is chosen as the copper source. Raab et al has found that NMI could improve the activity of $\mathrm{CuCl}_{2}$ greatly and reduce the corrosion of the autoclave[5].

Although the N-ligand is introduced to promote CuClx-catalyzed ( $\mathrm{x}=1$ or 2$)$ synthesis of DMC, there is no direct evidence for the promotion behavior of the ligand because of the difficulties to determine the structure and ingredient of the copper complexes, which are formed in situ in the oxidative carbonylation of methanol. Fundamentally, the central copper ion configuration is the key to understand the nature of the $\mathrm{Cu}$-catalyzed $\mathrm{DMC}$ formation.

Recently our research group found that $\mathrm{Cu}$ (phen) $\mathrm{Cl}_{2}$ (phen $=1,10$-phenanthroline) showed the higher catalytic activity for the DMC formation than the mixture of $\mathrm{CuCl}_{2}$ and phen[6]. In order to reveal the reason, we focus on the researches of relationship between the structures and the catalytic activity. In this paper, $\mathrm{Cu}$ (phen) $\mathrm{Cl}_{2},\left[\mathrm{Cu}\right.$ (phen) $\left.{ }_{2} \mathrm{Cl}\right] \mathrm{Cl} \cdot \mathrm{H}_{2} \mathrm{O}$ and $\left[\mathrm{Cu}(\text { phen })_{3}\right] \mathrm{Cl}_{2} \cdot 7 \mathrm{H}_{2} \mathrm{O}$ were prepared, and their catalytic properties were tested in the oxidative carbonylation of methanol to DMC.

\section{Experimental}

Chemical reagents. All reagents were purchased from local manufactures and used without further purification. $\mathrm{Cu}($ phen $) \mathrm{Cl}_{2},\left[\mathrm{Cu}(\text { phen })_{2} \mathrm{Cl}\right] \mathrm{Cl} \cdot \mathrm{H}_{2} \mathrm{O}$ and $\left[\mathrm{Cu}(\text { phen })_{3}\right] \mathrm{Cl}_{2} \cdot 7 \mathrm{H}_{2} \mathrm{O}$ were synthesized according to the literatures [1]. 
Catalyst characterization. Thermogravimetric analysis (TGA) was carried out on a TGA Q50 analyzer at a heating rate of $10{ }^{\circ} \mathrm{C} / \mathrm{min}$ from room temperature to $800^{\circ} \mathrm{C}$.

The CO-TPR analysis of $\mathrm{Cu}$ (phen) $\mathrm{Cl}_{2}$ was carried out on a Micro Auto Chem II 2920 at a heating rate of $10^{\circ} \mathrm{C} / \mathrm{min}$ from 45 to $300^{\circ} \mathrm{C}$.

Reaction procedure and product analysis. The oxidative carbonylation of methanol with $\mathrm{CO}$ and $\mathrm{O}_{2}$ was carried out in a $250 \mathrm{~mL}$ stainless steel autoclave. $40 \mathrm{~mL}$ of methanol and $0.011 \mathrm{~mol} / \mathrm{L}$ of the catalyst were loaded into the autoclave. The autoclave was purged three times with $\mathrm{O}_{2}$, and then pressurized to $4.0 \mathrm{MPa}$ with $\mathrm{CO}$ and $\mathrm{O}_{2}\left(P_{\mathrm{CO}} / P_{\mathrm{O} 2}=19: 1\right)$ at room temperature. The system was heated to $120^{\circ} \mathrm{C}$ and kept for $4 \mathrm{~h}$. After the reaction, the reactor was cooled to room temperature. The reaction mixture was analyzed by a GC-2014 (Shimadzu) equipped with a Rtx-50 capillary column (30 $\mathrm{m} \times$ $0.32 \mathrm{~mm} \times 0.25 \mu \mathrm{m})$ ) and flame ionization detector.

\section{Results and Discussion}

Effect of the thermal stability of the complex on the catalytic activity. The reaction temperature is usually over $110{ }^{\circ} \mathrm{C}$ in the oxidative carbonylation of methanol to $\mathrm{DMC}$, so the thermostability of $\mathrm{Cu}$ (II) complexes is a key. They were characterized by the thermogravimetric analysis.

It can be seen from Figure 1(a) that the weight loss of $\mathrm{Cu}$ (phen) $\mathrm{Cl}_{2}$ appears at $290{ }^{\circ} \mathrm{C}$. The loss is $57.5 \%$ in the $290 \sim 720{ }^{\circ} \mathrm{C}$ range, close to the $57.1 \%$ weight content of phen in $\mathrm{Cu}(\mathrm{phen}) \mathrm{Cl}_{2}$, so the temperature range should be ascribed to the decomposition of phen. This result implies that $\mathrm{Cu}$ (phen) $\mathrm{Cl}_{2}$ can meet the temperature requirement of the carbonylation reaction. $\left[\mathrm{Cu}(\mathrm{phen})_{2} \mathrm{Cl}\right] \mathrm{Cl}$ exhibits the $3.4 \%$ weight loss (seeing Figure 1(b)) from 80 to $180{ }^{\circ} \mathrm{C}$, implying that there is one crystal water in the complex. When the temperature is above $220{ }^{\circ} \mathrm{C}$, the loss may be attributed to its decomposition, so its thermal stability is also favorable to the oxidative carbonylation. In the TG patterns shown in Figure 1(c), the weight loss of $22.0 \%$ below $104{ }^{\circ} \mathrm{C}$ probably rises from the removal of crystal waters in $\left[\mathrm{Cu}(\text { phen })_{3}\right] \mathrm{Cl}_{2}$. The continuous weight loss should stem from its thermal degradation above $104{ }^{\circ} \mathrm{C}$. Thus the thermal stability of $\left[\mathrm{Cu}(\mathrm{phen})_{3}\right] \mathrm{Cl}_{2}$ is unfavorable to the oxidative carbonylation.

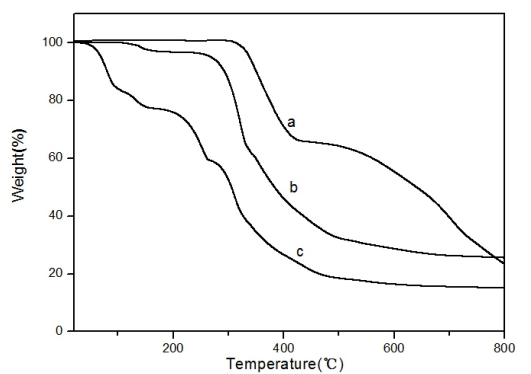

Fig. 1. TG patterns of $\mathrm{Cu}($ phen $) \mathrm{Cl}_{2}$ (a), $\left[\mathrm{Cu}(\text { phen })_{2} \mathrm{Cl}\right] \mathrm{Cl} \cdot \mathrm{H}_{2} \mathrm{O}\left(\right.$ b), $\left.\left[\mathrm{Cu}(\text { phen })_{3}\right] \mathrm{Cl}_{2}\right) \cdot 7 \mathrm{H}_{2} \mathrm{O}(\mathrm{c})$.

Catalytic performances of $\mathrm{Cu}$ complexes. In order to compare with the activity of $\mathrm{Cu}$ complexes, $\mathrm{CuCl}_{2}$ and the equimolar mixture of phen and $\mathrm{CuCl}_{2}$ were used to catalyze the oxidative carbonylation of methanol with $\mathrm{CO}$ and $\mathrm{O}_{2}$. The results are listed in Table 1. The turnover number (TON) was $16.3 \mathrm{~mol}_{\mathrm{DMC}} / \mathrm{mol}_{\mathrm{Cu}}$ with $\mathrm{CuCl}_{2}$ used as the catalyst, and the selectivity of DMC was $97.4 \%$. As a sole by-product, dimethoxymethane (DMM) was detected with the $2.6 \%$ selectivity. When the equimolar amount of phen was added, TON and the selectivity of DMC increased to 22.9 $\mathrm{mol}_{\mathrm{DMC}} / \mathrm{mol}_{\mathrm{Cu}}$ and $97.8 \%$, respectively. This suggests that the $\sigma-\pi$ coordination bond between phen and $\mathrm{Cu}(\mathrm{II})$ can improve the catalytic activity of $\mathrm{CuCl}_{2}$. However, when $\mathrm{Cu}$ (phen) $\mathrm{Cl}_{2}$ was used to catalyze the oxidative carbonylation of methanol, it is interesting to note that TON and the selectivity of DMC were improved further, up to $39.0 \mathrm{~mol}_{\mathrm{DMC}} / \mathrm{mol}_{\mathrm{Cu}}$ and $98.3 \%$, respectively. In order to explain the activity difference, the pre-treatment time of the mixture, referring to the mixed time of phen and $\mathrm{CuCl}_{2}$ before the reaction started, was investigated. As shown in Table 1, TON and the selectivity of DMC increased with the rise of the pre-treatment time, and were gradually close to 39.0 mol ${ }_{\mathrm{DMC}} / \mathrm{mol}_{\mathrm{Cu}}$ and $98.3 \%$. The results show that the reaction time is very important for the synthesis 
of $\mathrm{Cu}$ (phen) $\mathrm{Cl}_{2}$ from phen and $\mathrm{CuCl}_{2}$, and the conditions of the oxidative carbonylation are unfavorable to the in-situ synthesis of $\mathrm{Cu}(\mathrm{phen}) \mathrm{Cl}_{2}$.

Table 1 Effect of different catalysts on oxidative carbonylation of methanol

\begin{tabular}{ccccc}
\hline Catalyst & $\mathrm{S}_{\mathrm{DMC}}(\%)$ & $\begin{array}{c}\mathrm{S}_{\mathrm{DMM}} \\
(\%)\end{array}$ & $\begin{array}{c}\text { TON } \\
\left(\mathrm{mol}_{\mathrm{DMC}} / \mathrm{mol}_{\mathrm{Cu}}\right)\end{array}$ & $\begin{array}{c}\text { Pre-treatment time } \\
(\mathrm{min})\end{array}$ \\
\hline${ }^{*} \mathrm{CuCl}_{2}$ & 97.4 & 2.6 & 16.3 & 5 \\
${ }^{\mathrm{CuCl}}+$ phen & 97.8 & 2.2 & 22.9 & \\
${ }^{*} \mathrm{Cu}\left(\mathrm{phen}_{2}\right) \mathrm{Cl}_{2}$ & 98.3 & 1.7 & 39.0 & 10 \\
${ }^{*}{ }^{\mathrm{CuCl}} \mathrm{Cl}_{2}+$ phen & 98.0 & 2.0 & 26.1 & 20 \\
{$\left[\mathrm{Cu}(\text { phen })_{3}\right] \mathrm{Cl}_{2} \cdot 7 \mathrm{H}_{2} \mathrm{O}$} & 98.1 & 1.9 & 35.2 & \\
{$\left[\mathrm{Cu}(\text { phen })_{2} \mathrm{ClCl} \cdot \mathrm{H}_{2} \mathrm{O}\right.$} & $>99.9$ & 0 & 1.5 & \\
\hline
\end{tabular}

*The molar ratio of phen to $\mathrm{Cu}(\mathrm{II})$ is $1: 1$. Reaction Conditions: $V_{\mathrm{MeOH}} 50 \mathrm{~mL}, C_{\mathrm{Cu}}=0.011 \mathrm{~mol} / \mathrm{L}, 120{ }^{\circ} \mathrm{C}, 4 \mathrm{MPa}, 4 \mathrm{~h}$.

Detoni et al reported that the $\mathrm{Cu}$ complex with two phen $\left(\left[\mathrm{Cu}(\text { phen })_{2} \mathrm{Cl}\right] \mathrm{Cl}\right)$ showed the higher activity than $\mathrm{Cu}$ (phen) $\mathrm{Cl}_{2}$ and $\left.[\mathrm{Cu} \text { (phen })_{3}\right] \mathrm{Cl}_{2}$ in the oxidation of cyclohexane[7], so the effect of the structures of $\mathrm{Cu}$ complexes on the activity was also tested. TON on $\left[\mathrm{Cu}(\mathrm{phen})_{3}\right] \mathrm{Cl}_{2} \cdot 7 \mathrm{H}_{2} \mathrm{O}$ was only $1.5 \mathrm{~mol}_{\mathrm{DMC}} / \mathrm{mol}_{\mathrm{Cu}}$ (seeing Table 1), where the copper coordination environment is hexacoordination. Combined with Table 1 and Figure 1, we think that the low activity is probably caused by the following factors: firstly, the steric hindrance around $\mathrm{Cu}(\mathrm{II})$ is very large due to the formation of six $\mathrm{Cu}-\mathrm{N}$ bonds, thus the coordination of the complex with methanol or $\mathrm{CO}$ is inhibited, and the thermal stability of $\left[\mathrm{Cu}(\mathrm{phen})_{3}\right] \mathrm{Cl}_{2} \cdot 7 \mathrm{H}_{2} \mathrm{O}$ is also lowered because of the mutual repulsion from three phen rings (seeing Table 2); secondly, the saturation of the first coordination sphere reduces the probability of raw material molecules to be coordinated with $\mathrm{Cu}$ (II); thirdly, the catalytic performance of the complex is relevant to the $\sigma-\pi$ coordination bond between phen and $\mathrm{Cu}$, while the initial decomposition temperature of $\left.[\mathrm{Cu} \text { (phen) })_{3}\right] \mathrm{Cl}_{2} \cdot 7 \mathrm{H}_{2} \mathrm{O}$ is only $104^{\circ} \mathrm{C}$, implying that the $\sigma-\pi$ coordination bond is destroyed easily, so the catalytic activity decreases. With the decrease of the phen number, $\left[\mathrm{Cu}(\text { phen })_{2} \mathrm{Cl}\right] \mathrm{Cl} \cdot \mathrm{H}_{2} \mathrm{O}$, in which the copper center is pentacoordinated, has the low steric hindrance, the unsaturation of the first coordination sphere and labile positions occupied by $\mathrm{Cl}^{-}$, so the coordination probability is enhanced between $\left[\mathrm{Cu}(\text { phen })_{2} \mathrm{Cl}\right] \mathrm{Cl} \cdot \mathrm{H}_{2} \mathrm{O}$ and methanol or $\mathrm{CO}$. At the same time, its initial decomposition temperature increases to $220{ }^{\circ} \mathrm{C}$, indicating that the influence of the reaction temperature on the $\sigma-\pi$ coordination bond decreases. TON increased to $4.7 \mathrm{~mol}_{\mathrm{DMC}} /$ mol $_{\mathrm{Cu}}$. With the further decrease of the phen number, $\mathrm{Cu}(\mathrm{phen}) \mathrm{Cl}_{2}$, in which copper is tetracoordinated[1], has the lowest steric hindrance and the highest coordination probability stemming from the rise of the unsaturation of the first coordination sphere and labile positions occupied by $\mathrm{Cl}^{-}$, and the $290{ }^{\circ} \mathrm{C}$ initial decomposing temperature is also the highest, thus TON arrived to $39.0 \mathrm{~mol}_{\mathrm{DMC}} / \mathrm{mol}_{\mathrm{Cu}}$. However, the high activity of the $\mathrm{Cu}$ complex can also accelerate the rate of the side reaction, so the selectivity of $\mathrm{DMC}$ decreased gradually in the following order: $\mathrm{Cu}(\mathrm{phen}) \mathrm{Cl}_{2}$ $<\left[\mathrm{Cu}(\text { phen })_{2} \mathrm{Cl}\right] \mathrm{Cl} \cdot \mathrm{H}_{2} \mathrm{O}<\left[\mathrm{Cu}(\text { phen })_{3}\right] \mathrm{Cl}_{2} \cdot 7 \mathrm{H}_{2} \mathrm{O}$.

Table 2 The initial decompostion temperature and TON of the complexes

\begin{tabular}{ccc}
\hline Catalyst & Initial decomposition temperature $/\left({ }^{\circ} \mathrm{C}\right)$ & $\mathrm{TON} /\left(\mathrm{mol}_{\mathrm{DMC}} / \mathrm{mol}_{\mathrm{Cu}}\right)$ \\
\hline$\left[\mathrm{Cu}(\text { phen })_{3}\right] \mathrm{Cl}_{2} \cdot 7 \mathrm{H}_{2} \mathrm{O}$ & 104 & 1.5 \\
{$\left[\mathrm{Cu}(\text { phen })_{2} \mathrm{Cl}\right] \mathrm{Cl} \cdot \mathrm{H}_{2} \mathrm{O}$} & 220 & 4.7 \\
$\mathrm{Cu}($ phen $) \mathrm{Cl}_{2}$ & 290 & 39.0 \\
\hline
\end{tabular}

Effect of the addition of $\mathrm{CuCl}$. In the oxidative carbonylation of methanol, a mixed valence $\mathrm{Cu}(\mathrm{I}$, II)-ligand-bridged cluster is a key intermediate to form copper methoxycarbonyl species[6], so it is very necessary for the coexistence of $\mathrm{Cu}(\mathrm{II})$ and $\mathrm{Cu}(\mathrm{I}) . \mathrm{Cu}\left(\right.$ phen) $\mathrm{Cl}_{2}$ was characterized by the CO-TPR analysis and the pattern is shown in Figure 2. No peaks were detected in the $50 \sim 300^{\circ} \mathrm{C}$ range. The result demonstrates that it is impossible for the in-situ reduction of $\mathrm{Cu}(\mathrm{phen}) \mathrm{Cl}_{2}$ to $\mathrm{Cu}$ (phen) $\mathrm{Cl}$ under the reaction conditions. Therefore, the addition of $\mathrm{CuCl}$ may improve the activity of $\mathrm{Cu}$ (phen) $\mathrm{Cl}_{2}$. 


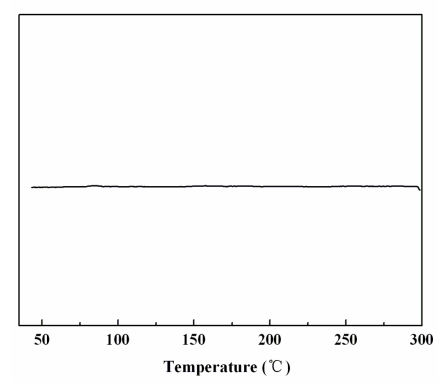
reaction

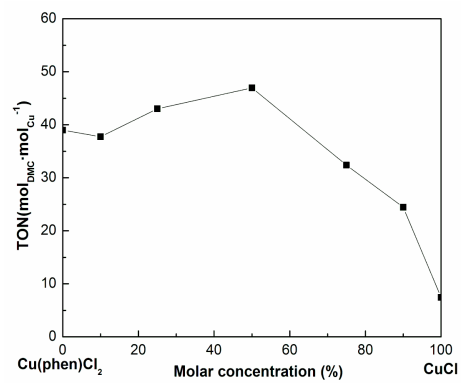

Fig. 3 Effect of the molar ratio of $\mathrm{Cu}$ (phen) $\mathrm{Cl}_{2}$ to $\mathrm{CuCl}$ on the

As shown in Figure 3, TON increased gradually with the addition of $\mathrm{CuCl}$. The result confirms the addition of $\mathrm{CuCl}$ is in favor of the synthesis of DMC. When the molar ratio of $\mathrm{Cu}$ (phen) $\mathrm{Cl}_{2}$ to $\mathrm{CuCl}$ is $1: 1$, the mixture catalyst revealed the highest activity. TON was up to $46.9 \mathrm{~mol}_{\mathrm{DMC}} / \mathrm{mol}_{\mathrm{Cu}}$, more than $39.0 \mathrm{~mol}_{\mathrm{DMC}} / \mathrm{mol}_{\mathrm{Cu}}$ over $\mathrm{Cu}($ phen $) \mathrm{Cl}_{2}$. Above $1: 1$, TON decreases due to the poor solubility of $\mathrm{CuCl}$ in methanol. Consequently, the optimal molar ratio of $\mathrm{Cu}($ phen $) \mathrm{Cl}_{2}$ to $\mathrm{CuCl}$ is $1: 1$.

\section{Conclusions}

Three $\mathrm{Cu}(\mathrm{II})-1,10$-phenanthroline complexes and the equimolar mixture of phen and $\mathrm{CuCl}_{2}$ were used as catalysts for the oxidative carbonylatiaon of methanol to DMC. It was found that the coordination environments and the thermal stability of complexes would influence the steric and electronic properties of the catalytic centers and the catalytic behaviors. $\mathrm{Cu}(\mathrm{phen}) \mathrm{Cl}_{2}$ exhibited the highest activity because of the lowest steric hindrance, the highest coordination probability and the highest thermal stability. TON reached to $39.0 \mathrm{~mol}_{\mathrm{DMC}} / \mathrm{mol}_{\mathrm{Cu}}$ with the $98.3 \%$ selectivity under the standard batch reaction conditions $\left([\mathrm{Cu}(\mathrm{II})]=0.011 \mathrm{~mol} \cdot \mathrm{L}^{-1}, 0.2 \mathrm{MPa} \mathrm{O}_{2}, 3.8 \mathrm{MPa} \mathrm{CO}, 120{ }^{\circ} \mathrm{C}\right.$ and 4 h). With the addition of $\mathrm{CuCl}$, the TON value of $\mathrm{DMC}$ was enhanced further to $46.9 \mathrm{~mol} \mathrm{DMC}_{\mathrm{DO}} / \mathrm{mol}_{\mathrm{Cu}}$.

\section{Acknowledgements}

This work was supported by the National Natural Science Foundation of China (21276201).

\section{References}

[1] Z.P. Du, L.H. Xiong, Z.K. Lin, Y.G. Ding, Y.X. Wu, Chin J Chem. Eng., 22 (2014) 1117-1121.

[2] D.H. Liu, J. He, L.B. Sun, X.Q. Liu. And Q Zhong, J. Taiwan Inst. Chem. Eng. 42 (2011) 616-621.

[3] W.L. Mo, , H. Xiong T. Li, X.C. Guo and G.X. Li, J. Mol. Catal. A: Chem. 247 (2006) 227-232.

[4] W.S. Dong, X.S. Zhou, C.S. Xin, C.L. Liu, and Z.T. Liu, Appl. Catal. A: Gen. 334 (2008) 100-105.

[5] V. Raab, M. Merz and J. Sundermeyer, Ligand effects in the copper catalyzed aerobic oxidative carbonylation of methanol to dimethyl carbonate (DMC), J. Mol. Catal. A: Chem. 175 (2001) 51-63.

[6] Z.P. Du, B. Zhou, L.M. Huang, C. H uang, Y.X. Wu, C.W. Wang, and W. Sun, Synthesis of

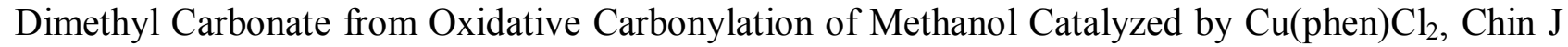
Catal. 33 (2012) 736-742.

[7] C. Detoni, N.M.F. Carvalho, D.A.G. Aranda, B. Louis, and O.A.C. Antunes, Appl. Catal. A: Gen. 365 (2009) 281-286. 